\title{
Curiosidades e desafios matemáticos nas aritméticas da série Concórdia
}

\author{
Malcus Cassiano Kuhn ${ }^{1}$
}

Arno Bayer ${ }^{2}$

\begin{abstract}
RESUMO
$\mathrm{O}$ artigo tem por objetivo discutir curiosidades e desafios matemáticos encontrados nas aritméticas da série Concórdia, editadas pela Igreja Luterana, na década de 1940, para suas escolas paroquiais, no Rio Grande do Sul. Baseando-se na pesquisa histórica, analisaram-se as edições da Primeira, Segunda e Terceira Aritmética, identificando-se curiosidades e desafios envolvendo: construção do significado de número até 10, quadrados mágicos, meses do ano, provas reais para as quatro operações elementares com números naturais, a prova dos 9 fora, exercícios de raciocínio lógico, contas curiosas e tabuada com frações. Embora algumas destas curiosidades e desafios estejam alicerçados no método de ensino intuitivo, os mesmos refletem a tradição pedagógica da memorização, destacando-se algoritmos e procedimentos de cálculos escritos e mentais, considerados fundamentais para que os futuros colonos fizessem a correta administração do orçamento familiar e o gerenciamento da sua propriedade rural.
\end{abstract}

PALAVRAS-CHAVE: Curiosidades. Desafios Matemáticos. Série Concórdia. Ensino da Matemática. Escolas Paroquiais Luteranas Gaúchas.

Curiosities and mathematical challenges in the arithmetic of the Concordia series

\begin{abstract}
The article aims to discuss curiosities and mathematical challenges found in the arithmetic of the Concordia series, edited by the Lutheran Church, in the 1940s, for their parochial schools in Rio Grande do Sul.
\end{abstract}

\footnotetext{
${ }^{1}$ Pós-doutorando do Programa de Pós-Graduação em Ensino de Ciências e Matemática da Universidade Luterana do Brasil, Canoas, Rio Grande do Sul, Brasil. Professor do Instituto Federal de Educação, Ciência e Tecnologia Sul-riograndense - IFSul, Câmpus Lajeado, Rio Grande do Sul, Brasil.E-mail: malcusck@ yahoo.com.br.

${ }^{2}$ Doutor em Ciências da Educação pela Universidade Pontifícia de Salamanca, Espanha. Professor e pesquisador do Programa de Pós-Graduação em Ensino de Ciências e Matemática da Universidade Luterana do Brasil, Canoas, Rio Grande do Sul, Brasil.E-mail: bayer@ulbra.br
} 
Basing on historical research, analyzed the editions of the First, Second and Third Arithmetic, identifying curiosities and challenges involving: construction of the meaning of number until 10, magic squares, months of the year, real proofs for the four elementary operations with natural numbers, the proof of 9 out, logical reasoning exercises, curious counts and multiplication tables with fractions. Although some of these curiosities and challenges are grounded in the intuitive teaching method, they reflect the pedagogical tradition of the memorization, highlighting algorithms and procedures of written and mental calculations, considered fundamental for that future colonists would did the correct administration of the family budget and the management of his rural property.

KEYWORDS: Curiosities. Mathematical Challenges. Concordia Series. Mathematics Teaching. Gaucho Lutheran Parochial Schools.

$$
* * *
$$

\section{Introdução}

O presente artigo tem por objetivo discutir curiosidades e desafios matemáticos encontrados nas edições da Primeira, Segunda e Terceira Aritmética, integrantes da série Concórdia, editadas pela Igreja Luterana na década de 1940, para suas escolas no Rio Grande do Sul - RS. Trata-se de um recorte de tese, complementado por pesquisas realizadas durante o estágio Pós-doutoral em um Programa de Pós-Graduação.

$\mathrm{O}$ movimento migratório no RS tem sido objeto de investigações. No âmbito da História da Educação no RS, os trabalhos de Kreutz (1991, 1994), Rambo (1994), Lemke (2001) e Weiduschadt (2007) são destaques. Na História da Educação Matemática no estado gaúcho, destacam-se as pesquisas de Mauro (2005), Wanderer (2007) e Kuhn (2015).

Conforme Prost (2008), os fatos históricos são constituídos a partir de traços deixados no presente pelo passado. Assim, a tarefa do historiador consiste em efetuar um trabalho sobre esses traços para construir os fatos. Como a temática investigada se insere na História da Educação Matemática 
no RS, busca-se na pesquisa histórica o suporte para discussão. Certeau (1982) define o fazer história, no sentido de pensar a história como uma produção. Para o autor, a história, como uma produção escrita, tem a tripla tarefa de convocar o passado que já não está em um discurso presente, mostrar as competências do historiador (dono das fontes) e convencer o leitor. O trabalho do historiador, de acordo com Certeau (1982), é fazer um diálogo constante do presente com o passado, e o produto desse diálogo consiste na transformação de objetos naturais em cultura.

Chervel (1990) considera importante o estudo histórico da cultura escolar para a compreensão dos elementos que participam da produção/elaboração/constituição dos saberes escolares e, em particular, da matemática escolar e sua história. Julia (2001) define a cultura escolar como um conjunto de normas que estabelecem conhecimentos a ensinar e condutas a inspirar, e um conjunto de práticas que permitem a transmissão desses conhecimentos e a incorporação desses comportamentos. De acordo com Valente (2007), pensar os saberes escolares como elementos da cultura escolar, realizar o estudo histórico da matemática escolar, exige que se devam considerar os produtos dessa cultura no ensino de matemática, que deixaram traços que permitem o seu estudo, como as aritméticas da série Concórdia, principais fontes documentais desta investigação.

Precedendo a discussão das curiosidades e dos desafios matemáticos encontrados nas aritméticas da série Concórdia, apresenta-se uma breve caracterização das escolas paroquiais luteranas gaúchas do século passado.

\section{As escolas paroquiais luteranas gaúchas do século $\mathrm{XX}$}

No Brasil, os princípios cristãos de Lutero, se fizeram presentes, a partir de 1824, com a vinda das ideias luteranas através dos primeiros imigrantes alemães. Lutero traçou princípios gerais sobre a educação, os quais se fundamentaram na Bíblia. "A premissa fundamental é de que a 
Bíblia ensina que Deus criou o universo e mantém, governa e sustenta toda a criação, sendo o homem a obra máxima da criação" (LEMKE, 2001, p. 34).

Nesta perspectiva luterana, o Sínodo Evangélico Luterano Alemão de Missouri $^{3}$, hoje Igreja Evangélica Luterana do Brasil - IELB, iniciou missão nas colônias alemãs do RS, em 1900, fundando congregações religiosas e escolas paroquiais. Para o Sínodo de Missouri era necessário consolidar um campo religioso e fortalecê-lo investindo na escola, influenciando o campo familiar dos seus possíveis fiéis. Por isso, os egressos das escolas paroquiais luteranas gaúchas tinham amplo conhecimento da Bíblia e uma formação consistente de crenças e valores cristãos tradicionais que enfatizavam a importância do relacionamento com Deus e com outras pessoas.

De acordo com Kuhn (2015), as escolas paroquiais luteranas estavam inseridas num projeto missionário e comunitário que buscava ensinar a língua materna, matemática, valores culturais, sociais e, principalmente, religiosos. Tinham uma responsabilidade para com a comunidade no sentido de, junto e com ela, promover o crescimento e o desenvolvimento pessoal de todos que a compõe, focando a cidadania. Se a escola formasse o ser humano com postura ética e moral exemplar, este poderia promover transformações sólidas em seu contexto social e seria um verdadeiro colaborador na seara de Deus e para o governo do mundo. As escolas paroquiais luteranas gaúchas foram assim caracterizadas por Weiduschadt (2007):

As escolas eram organizadas de forma multisseriada. As turmas eram compostas de 20 a 40 alunos. Na maioria das vezes, o pastor da comunidade era, ao mesmo tempo, professor. A comunidade sustentava a estrutura física e mantinham o professor da escola. $\mathrm{O}$ prédio era muitas vezes o mesmo local do templo. O projeto escolar dentro da comunidade religiosa era marcante, a orientação e a obrigação de os pais enviarem os filhos à escola eram quase

\footnotetext{
${ }^{3}$ Em 1847, um grupo de imigrantes luteranos alemães da Saxônia fundou no estado de Missouri (EUA), o Sínodo Evangélico Luterano Alemão de Missouri, Ohio e Outros Estados, atualmente Igreja Luterana - Sínodo de Missouri.
} 
obrigatórias, com sanções econômicas e morais, caso não concordassem. (WEIDUSCHADT, 2007, p. 166-168).

O Sínodo de Missouri também tinha uma preocupação acentuada em relação aos recursos didáticos usados nas escolas paroquiais, pois este material era escasso e a dificuldade era grande em manter um ensino planificado e organizado. De acordo com Weiduschadt (2007, p. 41), "os livros usados nas escolas paroquiais e utilizados pelos alunos foram produzidos pelas instituições religiosas com objetivo de formar e moldar as condutas e as práticas ao fazer a escolarização das comunidades”. Assim, por meio dos livros didáticos, como as aritméticas da série Concórdia, as escolas paroquiais luteranas gaúchas conseguiram desenvolver uma educação integral cristã em todas as disciplinas.

\section{As aritméticas da série Concórdia}

Conforme Kuhn (2015), o ensino da matemática, nos primeiros anos de escolarização nas escolas paroquiais luteranas gaúchas do século passado, priorizava os números naturais, os sistemas de medidas, as frações e os números decimais, complementando-se com a matemática comercial e financeira e a geometria. O ensino da matemática deveria acontecer de forma prática e articulada com as necessidades dos futuros agricultores, observando-se a doutrina luterana. Esta aparece e é reforçada nas aritméticas da série Concórdia através de exercícios e de problemas associados com operações comerciais (cálculo correto do troco) e com as quatro operações elementares (provas reais). Com este tipo de atividades, os autores das aritméticas esperavam que os alunos das escolas paroquiais preservassem valores, como a verdade e a honestidade, visando uma atuação consciente e responsável para sua subsistência e procurando o bem do próximo e da sociedade de acordo com a vontade de Deus. 
Nas escolas paroquiais luteranas do RS se dava ênfase aos Kopfrechnungen (cálculos feitos mentalmente), já que na vida agrícola a pessoa teria que calcular, com frequência, sem ter o papel e lápis à mão. $\mathrm{O}$ próprio título de um dos manuais usados nesta disciplina, o Praktische Rechenschule (o ensino prático da matemática), de Otto Büchler ${ }^{4}$, reflete este entendimento. Até aproximadamente 1932, predominava o ensino tradicional no Brasil. De 1932 até 1960, os alunos sofreram influências do evolucionismo e do pragmatismo, período denominado de Escola Nova.

Os primeiros 30 anos de existência das escolas paroquiais luteranas no RS foram marcados pela carência de materiais didáticos e progressiva adoção dos quatro manuais de Büchler, tanto em alemão, quanto em português, para as aulas de matemática. No periódico Unsere Schule (ago. $^{2}$ 1933, p. 6, tradução nossa), afirma-se que "os livros de aritmética de Büchler (editora Rotermund) ${ }^{6}$ são usados na maioria das nossas escolas e que a mesma editora lançou recentemente um novo manual: meu livro de contas, por W. Nast e L. Tochtrop". Na mesma edição, aponta-se a necessidade de uma edição com princípios morais e educacionais missourianos, uso de princípios pedagógicos modernos e adaptada às condições nacionais, pois o processo de nacionalização do ensino ${ }^{7}$ estava em curso.

Por isso, o Sínodo de Missouri começou a produzir seus próprios livros de aritmética na década de 1930. A Casa Publicadora Concórdia ${ }^{8}$ de Porto Alegre editou e publicou o material didático específico para as escolas paroquiais luteranas. Para as aulas de matemática, foram publicadas duas séries: a série Ordem e Progresso, lançada na década de 1930, pela

\footnotetext{
${ }^{4}$ Otto Büchler foi autor de livros de aritmética utilizados nas escolas teuto-brasileiras do século XX.

${ }^{5} \mathrm{Na}$ década de 1930, a IELB começou a publicar um periódico pedagógico dirigido às escolas paroquiais, chamado Unsere Schule (Nossa Escola), predominando informações e artigos escritos em alemão.

${ }^{6}$ A editora Rotermund, de São Leopoldo, editava e publicava o material didático relacionado ao Sínodo RioGrandense (Igreja Evangélica de Confissão Luterana no Brasil - IECLB).

${ }^{7}$ Uma série de decretos dos governos estadual e federal, emitidos no final da década de 1930, disciplinaram a licença de professores e o material didático a ser usado nas escolas, tornaram o idioma nacional obrigatório (português) para a instrução e prescreveram a formação cívica brasileira.

${ }^{8}$ Fundada em 1923, publicava livros e periódicos relacionados à literatura religiosa e escolar da IELB. Foi a primeira e a única redatora da IELB, existente até os dias atuais. Antes de sua fundação, os livros e periódicos eram impressos pela Concordia Publishing House, nos Estados Unidos, e enviados ao Brasil.
} 
divulgação feita no periódico Unsere Schule, e a série Concórdia, lançada na década de 1940.

A série Ordem e Progresso e a série Concórdia contém três aritméticas voltadas para o ensino da matemática nos primeiros anos de escolarização. No Instituto Histórico da IELB, em Porto Alegre, localizaramse a Primeira e a Terceira Aritmética da série Ordem e Progresso, além de uma edição da Primeira Aritmética, duas edições da Segunda Aritmética e uma edição da Terceira Aritmética da série Concórdia.

Neste artigo se realiza a discussão de curiosidades e desafios matemáticos encontrados nas aritméticas da série Concórdia, apresentadas no Quadro 1, tendo como base teórico-metodológica a pesquisa histórica.

QUADRO 1: Aritméticas analisadas.

\begin{tabular}{|c|c|c|c|}
\hline Obra & Data & Autor & Páginas \\
\hline Primeira Aritmética & {$\left[194^{-}\right]$} & Otto A. Goerl ${ }^{9}$ & 68 \\
\hline Segunda Aritmética & {$[194-]$} & Otto A. Goerl & 84 \\
\hline Segunda Aritmética & 1948 & Sem autoria declarada & 96 \\
\hline Terceira Aritmética & 1949 & Sem autoria declarada & 143 \\
\hline
\end{tabular}

Fonte: Série Concórdia.

Observa-se, no Quadro 1, que duas aritméticas possuem autoria declarada, um professor paroquial, e sobre os autores das demais obras não se obteve informações. Verifica-se que o número de páginas de cada aritmética aumenta conforme o nível de escolarização primária. Não se pode informar a quantidade de exemplares publicados em cada edição, pois esta informação não foi encontrada. Ressalta-se que as aritméticas da série Concórdia foram editadas com base em princípios morais e educacionais idealizados pela IELB.

\footnotetext{
9 O gaúcho Otto Adolpho Goerl (1905-1998) se formou no Seminário Concórdia (Instituto pedagógicoteológico que atuou na formação de pastores e professores paroquiais para IELB), em 1925, e foi ordenado pastor em 1926. Além de pastor, foi professor paroquial, professor e diretor do Seminário Concórdia. Autor de livros para o ensino de aritmética e leitura nas escolas paroquiais luteranas.
} 


\section{Curiosidades e desafios matemáticos nas aritméticas analisadas}

A Primeira Aritmética da série Concórdia aborda os números até 100. Exploram-se as operações de adição, subtração, multiplicação e divisão, e a pequena tabuada. $\mathrm{O}$ autor dessa aritmética dá maior ênfase para o método intuitivo em suas propostas de ensino, mas também traz atividades que enfatizam a memorização. O estudo da numeração até 10 é proposto de forma intuitiva pelo autor, associando-se quantidades de animais, pessoas ou objetos à representação simbólica do número, seguida de cálculos que envolvem as operações de adição ou subtração até 10. A Figura 1 ilustra a proposta de estudo para o número 6:

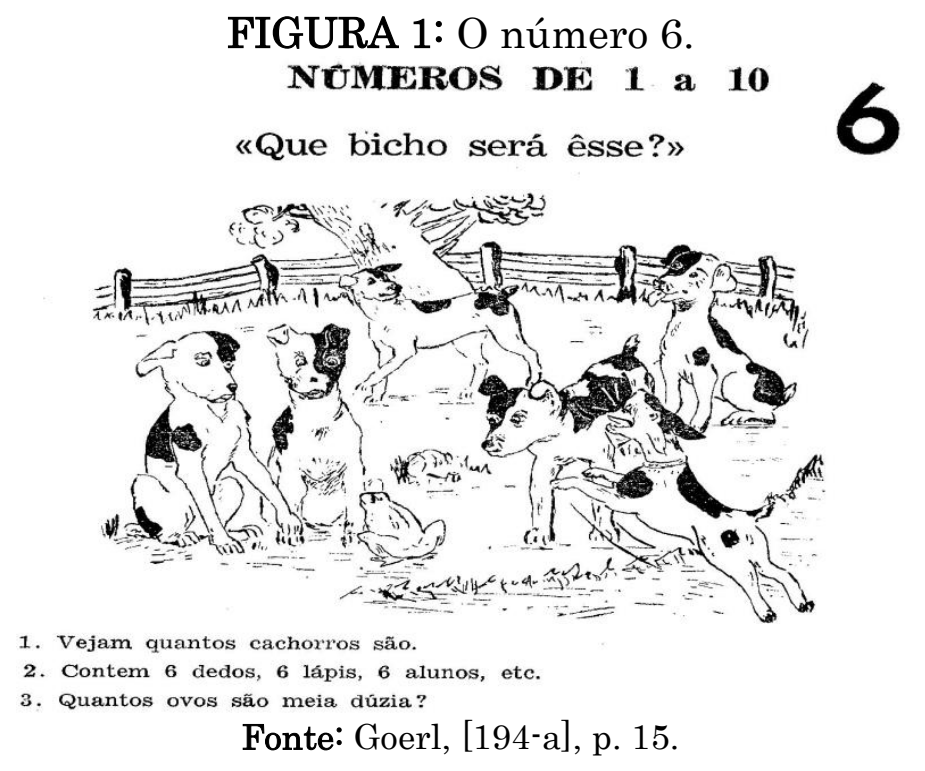

Observa-se que o autor emprega o método de ensino intuitivo para construção do conceito de número, associando o número 6 com a representação de 6 cachorros, propondo a contagem de 6 dedos, 6 lápis e 6 alunos, além de envolver a unidade de medida dúzia. Empregando o método de ensino intuitivo, o autor esperava que os alunos das escolas paroquiais luteranas gaúchas se apropriassem do significado de número.

A Segunda Aritmética de Goerl [194-b] está dividida em três seções: números de 1 a 100 (recapitulação); números de 1 a 1000; números até 10000. Mesmo que o autor desta aritmética proponha a resolução de 
problemas contextualizados com a realidade dos alunos das escolas paroquiais luteranas gaúchas, observam-se propostas de ensino para o desenvolvimento de habilidades para o cálculo mental e escrito, envolvendo as quatro operações elementares com números naturais.

$\mathrm{Na}$ análise realizada, verificou-se que essa aritmética traz atividades com quadrados mágicos, conforme descrito no Quadro 2:

QUADRO 2: Quadrados mágicos.

Num quadrado mágico a soma dos números em linha horizontal, vertical e diagonal é sempre igual.

\begin{tabular}{|l|l|l|}
\hline 4 & 9 & 2 \\
\hline 3 & 5 & 7 \\
\hline 8 & 1 & 6 \\
\hline
\end{tabular}

2.

\begin{tabular}{|l|l|l|}
\hline 8 & 3 & \\
\hline & 5 & \\
\hline & & \\
\hline
\end{tabular}

3.

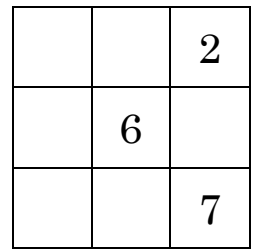

1. Somem, no quadrado mágico número 1, os números de cima para baixo, da esquerda para a direita e de um canto para o outro. Que resultado terão?

2. O resultado do número 2 também é 15 . Coloquem os números que faltam, começando com a linha horizontal, passando então para a vertical, e assim por diante.

3. Façam o mesmo com o quadrado número 3, cujo resultado é 18 . Depois da vertical somem a diagonal. Daí em diante será fácil.

4.

\begin{tabular}{|l|l|l|}
\hline & 8 & \\
\hline & 4 & \\
\hline & 0 & 5 \\
\hline
\end{tabular}

5 .

\begin{tabular}{|c|c|c|}
\hline 6 & & \\
\hline 11 & 7 & \\
\hline 4 & & \\
\hline
\end{tabular}

6. 7

\begin{tabular}{|l|l|l|l|}
\hline 7 & & 1 & 14 \\
\hline & 13 & 8 & \\
\hline 16 & 3 & & \\
\hline & & & 4 \\
\hline
\end{tabular}

4. Descobrir a soma de cada linha. Coloquem os números que faltam.

5. Façam o mesmo com o número 5. Não esqueçam a diagonal.

6. O quadrado número 6 tem por soma 34. Coloquem os números que faltam começando com a diagonal.

\section{Fonte: Goerl, [194-b], p. 40.}

Observa-se que, após uma breve sistematização sobre os quadrados mágicos, o autor propõe atividades com seis quadrados mágicos, sendo cinco deles $3 \times 3$ e um deles $4 \times 4$. Também não se explora a origem dos quadrados 
mágicos ${ }^{10}$, mas se tratam de atividades desafiadoras para os alunos e uma estratégia que pode incentivar a curiosidade e o gosto pela matemática. A Segunda Aritmética de 1948 também apresenta exercícios envolvendo quadrados mágicos, sendo dois deles 4 x 4 e um deles 5 x 5 .

O recorte da Segunda Aritmética de Goerl, apresentado na Figura 2, apresenta informações sobre a quantidade de dias dos meses do ano:

FIGURA 2: Número de dias dos meses do ano.

\begin{abstract}
Notem bem: Na aritmética o més conta 30 dias. Seguindo, porém, o calenđário veremos que alguns meses têm 31 dias e o fevereiro apenas 28 dlas. Vejam como ê fácil saber os dias de cada mệs.
\end{abstract}

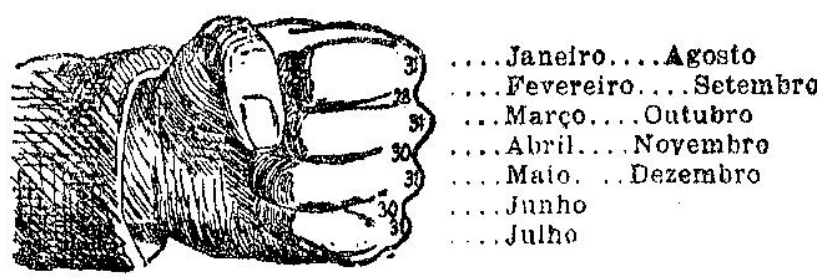

Fonte: Goerl, [194-b], p. 60.

O fragmento do livro, observado na Figura 2, mostra quantos dias tem um mês utilizando os nós superiores dos dedos e os seus intervalos. A cada nó, intercalado com o intervalo com o próximo nó, é atribuído sequencialmente um mês, começando pelo mês de janeiro. O número de dias é dado da seguinte forma: se o mês está num nó do dedo, terá 31 dias; se o mês está num intervalo, então terá 30 dias, à exceção de fevereiro, que poderá ter 29 ou 28 dias, consoante seja ano bissexto ou não, respectivamente. Aponta-se que o livro traz uma informação incompleta, pois não faz referência ao mês de fevereiro com 29 dias em anos bissextos. Ressalta-se que esta associação e a informação incompleta sobre o número de dias do mês de fevereiro, também foram observadas na edição da Segunda Aritmética de 1948. A associação proposta pelo autor pode auxiliar o aluno na memorização da quantidade de dias em cada mês do ano, utilizando-se de partes do corpo humano no ensino da matemática.

\footnotetext{
10 "Um dos primeiros registros de um quadrado mágico apareceu na China. Conta a lenda que o quadrado foi trazido aos homens por uma tartaruga, através do Rio Lo, há mais de 4000 anos" (CARVALHO, 1997, p. 58).
} 
$\mathrm{Na}$ antepenúltima página dessa aritmética, Goerl [194-b] propõe 15 perguntas divertidas para os alunos, conforme os exemplos no Quadro 3:

QUADRO 3: Perguntas divertidas.

\begin{tabular}{|c|c|}
\hline $\begin{array}{l}\text { Pensem bem antes de responder! } \\
\text { 1) Tenho } 2 \text { irmãos e } 2 \text { irmãs. Quantos filhos tên } \\
\text { 2) Uma choca tinha } 12 \text { pintos; } 2 \text { morreram e os } \\
\text { uantos pintos a choca tem ainda? } \\
\text { 3) Um ovo leva } 4 \text { minutos para cozinhar. Qu } \\
\text { vos? } \\
\text { 4) Um homem leva } 3 \text { horas para ir a pé da sua } \\
\text { oras levam } 4 \text { homens? } \\
\text { 5) Um homem ia a São Leopoldo. Vêm ao se } \\
\text { ada uma leva } 3 \text { gatos, e cada gato } 3 \text { gatinhos. } \\
\text { 6) João tinha } 3 \text { bolas. Disse ele a Pedro: Se eu } \\
\text { dobro do que você tem. Quantas bolas tem Pedro } \\
\text { Respostas elaboradas pelos autores do artigo: } \\
\text { 1) } 5 \text { filhos. } \\
\text { 2) Nenhum pinto. } \\
\text { 3) } 4 \text { minutos se todos forem cozinhados juntos. }\end{array}$ & $\begin{array}{l}\text { s ficaram grandes. } \\
\text { minutos levam } 5 \\
\text { até à vila. Quantas } \\
\text { ontro } 3 \text { mulheres. } \\
\text { os são ao todo que } \\
\text { e mais } 1 \text { bola teria } \\
\text { 4) } 3 \text { horas. } \\
\text { 5) } 1 \text { homem. } \\
\text { 6) } 2 \text { bolas. }\end{array}$ \\
\hline
\end{tabular}

Fonte: Goerl, [194-b], p. 82.

Estas perguntas divertidas são desafios que exigem a atenção dos alunos - pensem bem antes de responder! - e incentivam o raciocínio lógico. A Segunda Aritmética de 1948 também traz desafios de raciocínio lógico, intitulados como charadas. Acredita-se que propostas de ensino envolvendo uma matemática mais lúdica tenham sido uma estratégia dos autores para aguçar a curiosidade dos alunos e incentivar o seu gosto pela matemática.

A edição da Segunda Aritmética, editada em 1948, traz como principais unidades de estudo: numeração 1 - 1000; os números até 10000; números além de 10000. Nesta aritmética, focam-se as quatro operações elementares com números naturais para o desenvolvimento de habilidades para o cálculo mental e escrito.

Nessa aritmética se encontrou o seguinte exercício: "Somar a 97 tantas vezes 129 até se alcançar 1000” (SÉRIE CONCÓRDIA, 1948, p. 32). Uma versão semelhante deste exercício é citada por Gans (2013, apud KUHN, 2015), que estudou na escola paroquial de Linha Brasil, Nova 
Petrópolis/RS, no período de 1936 a 1941, ao falar sobre as aulas de matemática:

[...] Os conteúdos da $2^{\mathrm{a}}$ série eram somas e subtrações mais complexas e contas tripas ${ }^{11}$, além dos números até 1000. [...] As contas tripas eram, por exemplo, somar 7 ao número 23 até chegar ao número 233, ou subtrair 7 do número 210 até chegar a zero:

\begin{tabular}{lc}
23 & 210 \\
+7 & -7 \\
30 & 203 \\
+7 \\
37 & -7 \\
+7 \\
44 & -79 \\
+7 & 189 \\
51 etc. & -7 \\
\hline
\end{tabular}

Enquanto fazíamos essas contas, o professor atendia outra série ${ }^{12}$ [...]. (GANS, 2013, apud KUHN, 2015, p. 253).

Verifica-se que o exercício encontrado na Segunda Aritmética é uma conta tripa, pois é necessário somar 7 vezes a parcela 129 ao 97 para se obter 1000. Acredita-se que este tipo de exercício, bem como os demais exercícios de cálculo, geralmente em grande quantidade nas aritméticas analisadas, ajudavam a manter os alunos de uma série ocupados enquanto o professor atendia outra série, nas escolas paroquiais luteranas gaúchas com turmas multisseriadas.

No Quadro 4 são descritas as provas reais da adição e subtração, localizadas na Segunda Aritmética de 1948:

\footnotetext{
${ }^{11}$ Eram contas compridas de adição ou subtração com algoritmo na vertical. Partia-se de uma quantia e através de somas ou subtrações constantes e sucessivas se chegava a outra quantia determinada.

${ }^{12}$ Essa escola era multisseriada, ou seja, um único professor atendia mais de uma série na mesma sala de aula e no mesmo turno.
} 
QUADRO 4: Provas reais da adição e subtração.

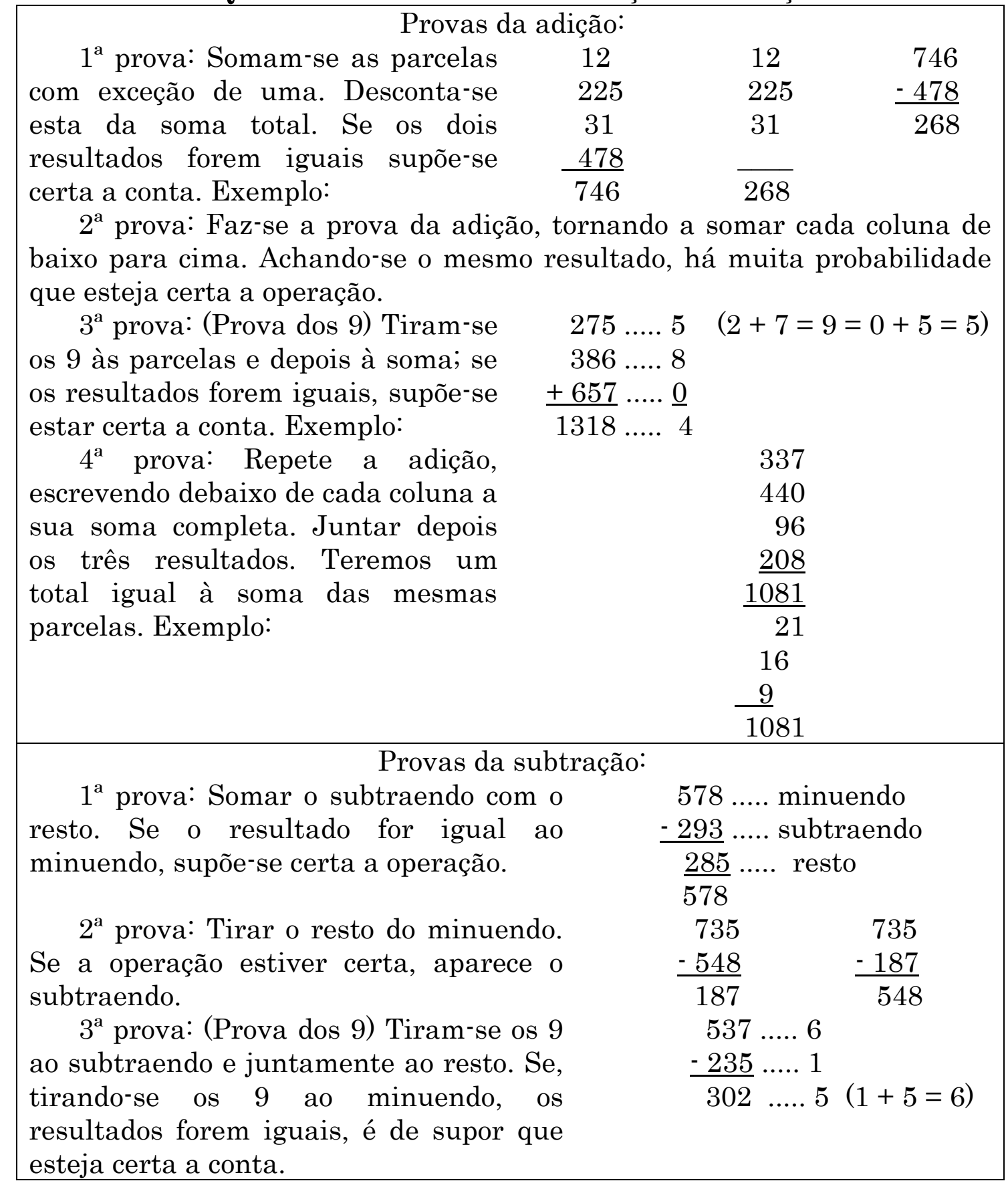

Fonte: Série Concórdia, 1948, p. 56-57.

O Quadro 4 apresenta quatro modos de fazer a prova real nos cálculos de adição e três maneiras de realizar a prova real nos cálculos de subtração, inclusive a prova dos 9 . Observa-se que a $1^{\text {a }}$ prova da adição e as duas primeiras provas da subtração exploram a ideia da adição e subtração como operações inversas para fazer a verificação dos cálculos escritos. A $2^{\mathrm{a}}$ prova da adição propõe a realização das somas em ordem inversa, verificando-se o 
resultado quando a soma de cima para baixo for igual à soma de baixo para cima das parcelas. A $4^{\mathrm{a}}$ prova da adição explora o sistema decimal com a composição de centenas, dezenas e unidades e de forma subentendida, o uso do quadro valor lugar (QVL) para verificar a operação de adição.

A $3^{\mathrm{a}}$ prova da adição e subtração é a prova dos 9. De acordo com Lavaca e Costa (2016, p. 58), "tirar os 9 fora de um número natural qualquer n, significa subtrair deste número o maior múltiplo de 9 nele contido, o que é equivalente a encontrar o resto da divisão deste número n por 9”. De forma prática, pode-se somar os algarismos deste dado número que se deseja obter os 9 fora, obtendo outro valor. A partir deste novo valor, somam-se novamente os algarismos e assim por diante até restar um número de um algarismo.

No caso da adição, tiram-se os 9 das parcelas e das somas, se os resultados forem iguais, supõe-se que a soma esteja verificada.

Exemplo da prova dos 9 para a adição:

$$
\begin{aligned}
& 275 \ldots . .2+7=9-9=0+5=5 \\
& 386 \ldots . .3+8=11-9=2+6=8 \\
& 5+8+0=13-9=4 \\
& +657 \ldots .6+5=11-9=2+7=9-9= \\
& 1318 \ldots . .1+3+1+8=13-9=4
\end{aligned}
$$

$\mathrm{Na}$ subtração, tiram-se os 9 do minuendo, do subtraendo e do resto. Então, se a soma do subtraendo com o resto foi igual ao minuendo, acreditase que o cálculo esteja correto.

Exemplo da prova dos 9 para a subtração:

$$
\left.\begin{array}{rl}
537 \ldots . .5+3+7 & =15-9=6 \\
-235 \ldots . .2+3+5 & =10-9=1 \\
302 \ldots . .3+0+2 & =5
\end{array}\right] 1+5=6
$$

Como $6=6$, acredita-se que a subtração esteja correta.

Ressalta-se que esta proposta de ensino do livro está centrada nos procedimentos e algoritmos para verificação da prova real de cada operação matemática. Essas atividades evidenciam uma proposta pedagógica que 
desenvolve habilidades para cálculos escritos com precisão nas escolas paroquiais luteranas, pois as aritméticas da série Concórdia desenvolvem, gradativamente, as operações de adição, subtração, multiplicação e divisão, culminando seu estudo com as provas reais destas operações. No Quadro 5 se apresentam as provas reais para a operação de multiplicação:

QUADRO 5: Provas reais para multiplicação.

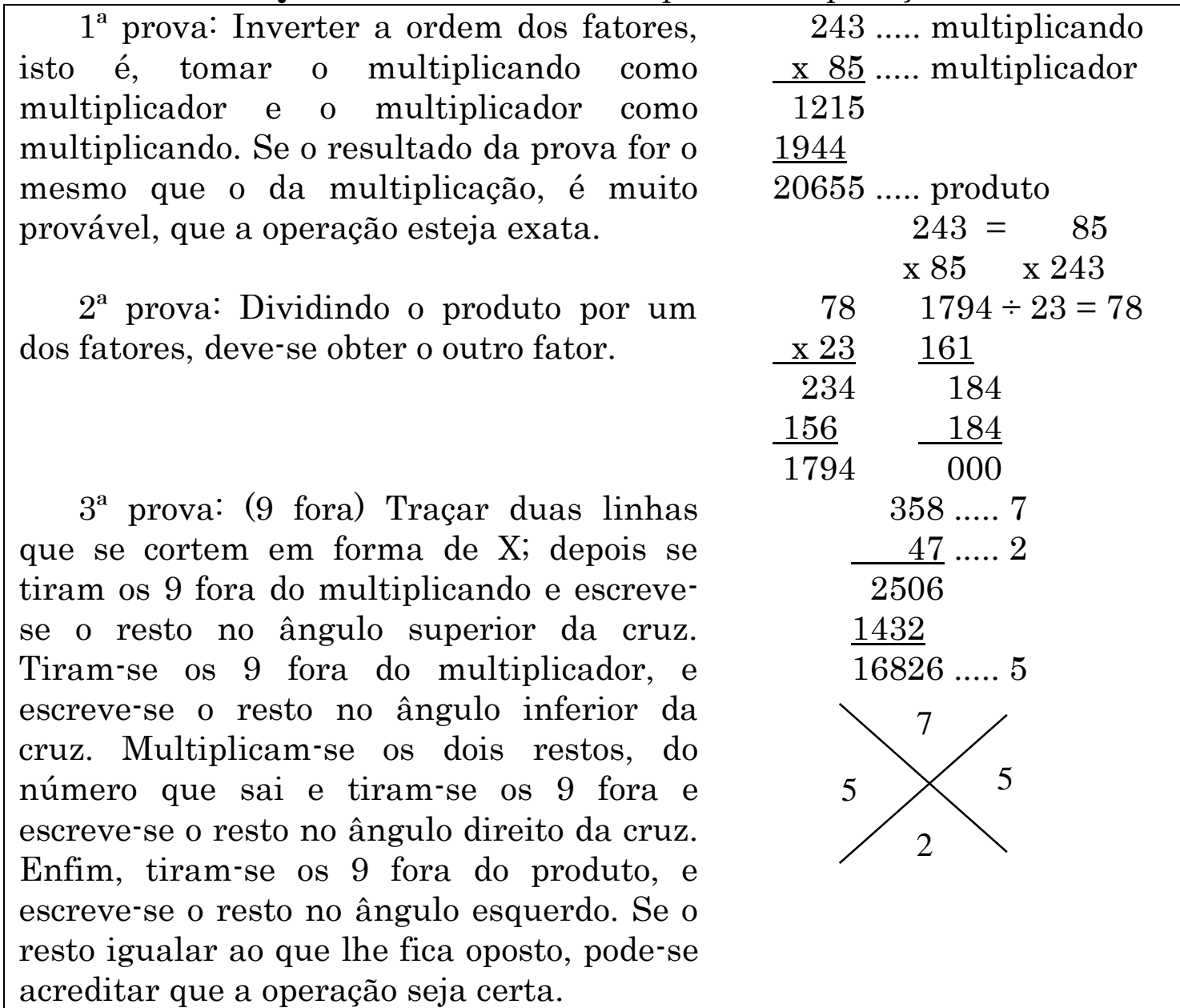

Fonte: Série Concórdia, 1948, p. 90.

O livro aborda três provas reais para a operação de multiplicação, apresentando-se os algoritmos e os procedimentos para realização da prova real em multiplicações. A $1^{\mathrm{a}}$ prova consiste em inverter a ordem dos fatores para verificar o produto. A $2^{\mathrm{a}}$ prova envolve a divisão como operação inversa da multiplicação e a $3^{\text {a }}$ prova é a dos 9 fora, conforme descrito no Quadro 5.

A Segunda Aritmética de 1948 ainda traz as provas reais para a operação de divisão, conforme apresentado no Quadro 6: 
QUADRO 6: Provas reais para divisão.

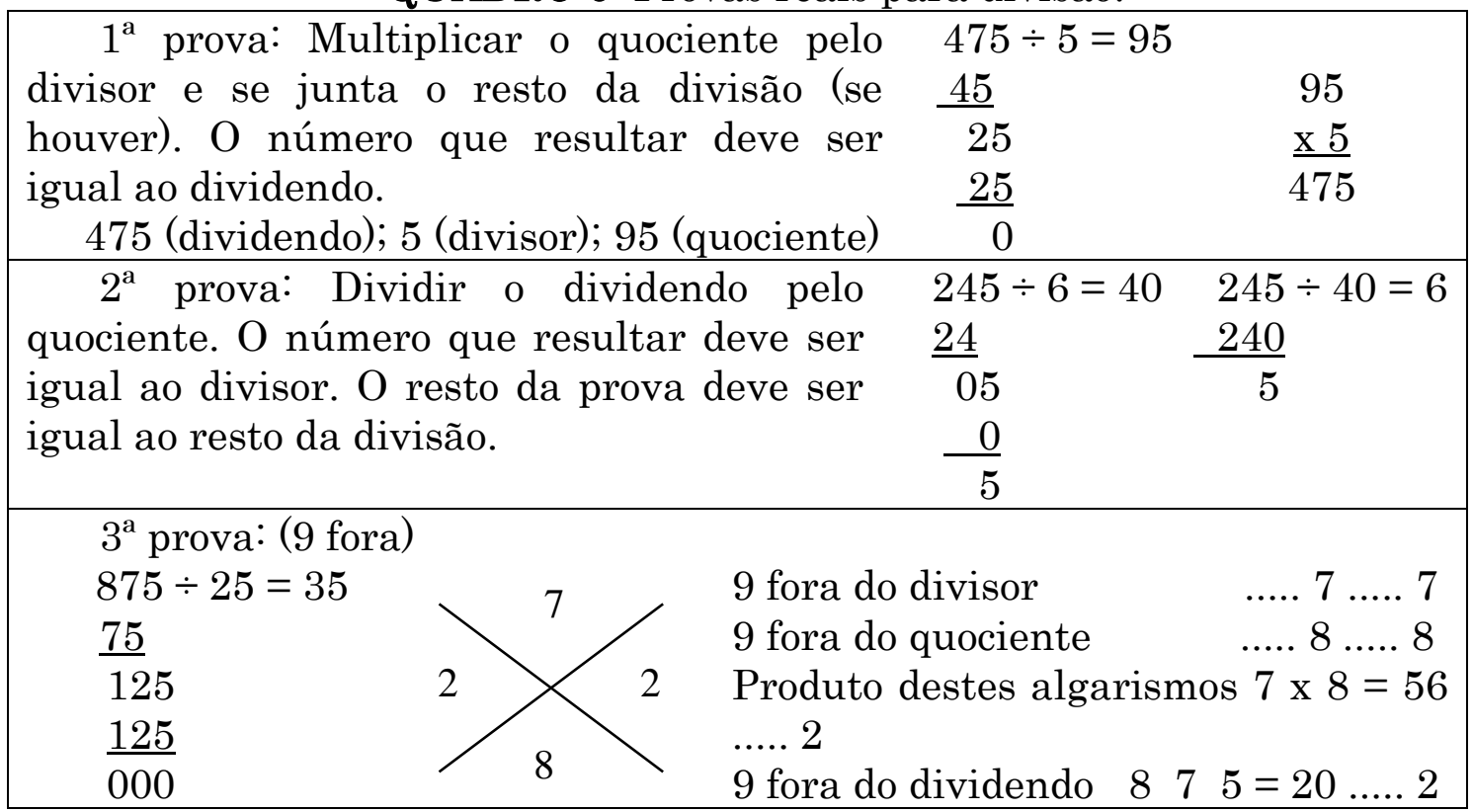

Fonte: Série Concórdia, 1948, p. 91.

O Quadro 6 mostra como o livro aborda as três provas reais para a operação de divisão, apresentando-se os algoritmos e os procedimentos para realização da prova real em divisões. A $1^{\mathrm{a}}$ prova envolve a multiplicação como operação inversa da divisão. A $2^{a}$ prova consiste em dividir o dividendo pelo quociente obtido, devendo-se obter um resultado igual ao divisor e os restos da prova e da divisão devem ser iguais. A $3^{\mathrm{a}}$ prova é dos 9 fora, conforme descrito no excerto acima.

A partir das três provas de multiplicação e divisão apresentadas, ressalta-se que a proposta da Segunda Aritmética de 1948 enfatiza os algoritmos e os procedimentos para verificação da prova real de cada operação matemática, na intenção de desenvolver habilidades nos alunos para o cálculo escrito e mental, refletindo-se a tradição pedagógica da memorização (VALENTE; PINHEIRO, 2015).

A Segunda Aritmética de 1948 apresenta uma conta curiosa, conforme descrito no Quadro 7: 
QUADRO 7: Conta curiosa.

$$
\begin{aligned}
& 9 \times 1+1=10 \\
& 9 \times 12+2=110 \\
& 9 \times 123+3= \\
& 9 \times 1234+4= \\
& 9 \times 12345+5= \\
& 9 \times 123456+6= \\
& 9 \times 1234567+7= \\
& 9 \times 12345678+8= \\
& 9 \times 123456789+9=
\end{aligned}
$$

Fonte: Série Concórdia, 1948, p. 93.

Esta conta curiosa, encontrada no livro, envolve as operações de multiplicação por 9 e de adição dos números naturais de 1 a 9 . Verifica-se que os resultados de cada cálculo possuem a quantidade de algarismos 1 correspondente a parcela somada, acrescidos do algarismo 0. Por exemplo, 9 x $123456+6=1111110$ ( 6 vezes o algarismo 1 acrescido do 0 ). Novamente se observa a instrumentalização dos alunos para o cálculo, porém, isto é feito de maneira curiosa com o emprego de regularidades.

As principais unidades de estudo da edição da Terceira Aritmética são: frações decimais e sistema métrico; frações ordinárias; regra de três; porcentagem; porcentagem comercial; juros; razão e proporção; geometria prática. Essa aritmética é caracterizada por apresentar propostas de estudo mais sistematizadas dos conhecimentos matemáticos.

Nessa edição se observaram registros relacionados à tabuada com frações, conforme mostrado no Quadro 8:

QUADRO 8: Tabuada com frações.

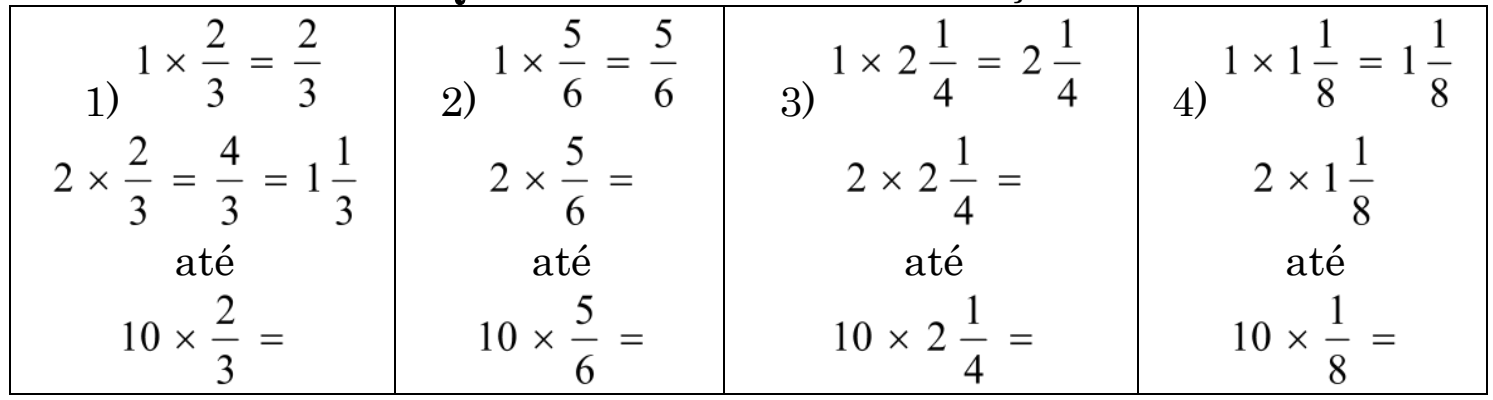

Fonte: Série Concórdia, 1949, p. 51. 
O Quadro 8 apresenta uma proposta com quatro exercícios de tabuada com as frações ordinárias $\frac{2}{3}, \frac{5}{6}, 2 \frac{1}{4}$ e $1 \frac{1}{8}$. Ressalta-se que as atividades também envolvem números mistos com a representação de frações impróprias como números mistos e vice versa. Este tipo de exercício reforça a ideia de que no ensino da matemática nas escolas paroquiais luteranas gaúchas havia uma preocupação com o desenvolvimento de habilidades para o cálculo mental e escrito.

A análise das aritméticas da série Concórdia, direcionadas para as escolas paroquiais luteranas gaúchas, no século passado, permitiu um adentramento na cultura escolar num lugar e num tempo determinados, identificando-se curiosidades e desafios matemáticos nesse contexto.

\section{Considerações finais}

Partindo da base teórico-metodológica da pesquisa histórica se investigaram curiosidades e desafios matemáticos encontrados em quatro aritméticas da série Concórdia, editadas pela IELB, através da Casa Publicadora Concórdia, na década de 1940, para suas escolas paroquiais no RS. Neste contexto missionário e de formação geral, a Igreja Luterana editou livros didáticos de acordo com seus princípios morais e educacionais, adaptando-se ao processo de nacionalização do ensino.

Na análise da Primeira Aritmética se identificou que o autor propôs a construção do significado de número pelo método de ensino intuitivo, evidenciando-se a estratégia de associar cada número até $10 \mathrm{com}$ animais ou objetos do cotidiano dos alunos. Na edição da Segunda Aritmética, Goerl propõe a resolução de quadrados mágicos, curiosidades sobre o número de dias dos meses do ano e exercícios de raciocínio lógico. $\mathrm{Na}$ Segunda Aritmética de 1948 se observaram quadrados mágicos, charadas para o desenvolvimento do raciocínio lógico, contas compridas de adição ou subtração com algoritmo na vertical, provas reais para as operações de 
adição, subtração, multiplicação e divisão com números naturais - inclusive a prova dos 9 fora, além de contas curiosas. Na edição da Terceira Aritmética chamou atenção a tabuada com frações. As curiosidades e os desafios nestas três aritméticas são marcados por cálculos escritos e mentais, destacando-se os algoritmos e os procedimentos das provas reais para as quatro operações elementares.

Mesmo que as aritméticas da série Concórdia tenham sido editadas num período marcado pelo movimento da Escola Nova no Brasil e que, algumas curiosidades e desafios matemáticos estejam alicerçadas no método de ensino intuitivo, as mesmas ainda refletem a tradição pedagógica da memorização. Isto está associado ao fato de que o ensino da matemática nas escolas paroquiais luteranas gaúchas do século passado foi caracterizado pelo desenvolvimento de habilidades para o cálculo mental e escrito, de forma prática e contextualizada, para que os futuros colonos fizessem a correta administração do orçamento familiar e o gerenciamento da sua propriedade rural. Ressalta-se que algumas dessas tarefas desafiadoras (curiosidades e desafios matemáticos), localizadas nas aritméticas da série Concórdia, ainda estão presentes em livros de matemática atuais e em obras como as de Malba Tahan.

\section{Referências}

CARVALHO, M. C. C. S. Padrões numéricos e sequências. São Paulo: Moderna, 1997.

CERTEAU, M. A escrita da História. Tradução Maria de Lourdes Menezes. Rio de Janeiro: Forense Universitária, 1982.

CHERVEL, A. História das disciplinas escolares - reflexões sobre um campo de pesquisa. Teoria \& Educação, Porto Alegre, n. 2, p. 177-229, 1990.

GOERL, O. A. Série Concórdia: Primeira Aritmética. Porto Alegre: Casa Publicadora Concórdia, [194-a].

- Série Concórdia: Segunda Aritmética. Porto Alegre: Casa Publicadora Concórdia, [194-b]. 
JULIA, D. A cultura escolar como objeto histórico. Revista Brasileira de História da Educação, Campinas, n. 1, p. 9-43, jan./jun. 2001.

KREUTZ, L. O professor paroquial: magistério e imigração alemã. Porto Alegre: Ed. da UFRGS; Caxias do Sul: EDUCS, 1991.

. Material didático e currículo na escola teuto-brasileira. São Leopoldo: Ed. UNISINOS, 1994.

KUHN, M. C. O ensino da matemática nas escolas evangélicas luteranas do Rio Grande do Sul durante a primeira metade do século XX. 2015. 466 f. Tese (Doutorado em Ensino de Ciências e Matemática) - Universidade Luterana do Brasil, Canoas.

LAVACA, A. G.; COSTA, D. A. A prova dos nove e o caso da "Arithmetica Primaria" de Cezar Pinheiro. REVEMAT, Florianópolis, v. 11, n. 1, p. 54-73, 2016.

LEMKE, M. D. Os princípios da educação cristã luterana e a gestão de escolas confessionárias no contexto das ideias pedagógicas no sul do Brasil (1824 - 1997). Canoas: Ed. ULBRA, 2001.

MAURO, S. Uma história da matemática escolar desenvolvida por comunidades de origem alemã no Rio Grande do Sul no final do século XIX e início do século XX. 2005. 257 f. Tese (Doutorado em Educação Matemática) - Universidade Estadual Paulista, Rio Claro.

PROST, A. Doze lições sobre a História. Belo Horizonte, Autêntica, 2008.

RAMBO, A. B. A escola comunitária teuto-brasileira católica. São Leopoldo: Ed. UNISINOS, 1994.

SÉRIE Concórdia: Segunda Aritmética. Porto Alegre: Casa Publicadora Concórdia, 1948.

SÉRIE Concórdia: Terceira Aritmética. Porto Alegre: Casa Publicadora Concórdia, 1949.

UNSERE SCHULE. Porto Alegre: Casa Publicadora Concórdia, 1933-1935.

VALENTE, W. R. História da Educação Matemática: interrogações metodológicas. REVEMAT - Revista Eletrônica de Educação Matemática, UFSC, v. 2.2, p. 28-49, 2007.

; PINHEIRO, N. V. L. Chega de decorar a tabuada! - As cartas de Parker e a árvore do cálculo na ruptura de uma tradição. Educação Matemática em Revista $R S$, Canoas, v. 1, n. 16, p. 22-37, 2015.

WANDERER, F. Escola e Matemática Escolar: mecanismos de regulação sobre sujeitos escolares de uma localidade rural de colonização alemã no Rio Grande do 
Sul. 2007. 228 f. Tese (Doutorado em Educação) - Universidade do Vale do Rio dos Sinos, São Leopoldo.

WEIDUSCHADT, P. O Sínodo de Missouri e a educação pomerana em Pelotas e São Lourenço do Sul nas primeiras décadas do século XX: identidade e cultura escolar. 2007. 255 f. Dissertação (Mestrado em Educação) - Universidade Federal de Pelotas, Pelotas.

Recebido em dezembro de 2016.

Aprovado em janeiro de 2018. 